\title{
Heme oxygenase-1-mediated neuroprotection in subarachnoid hemorrhage via intracerebroventricular deferoxamine
}

\author{
Robert H. LeBlanc III', Ruiya Chen ${ }^{1}$, Magdy H. Selim ${ }^{1}$ and Khalid A. Hanafy ${ }^{1,2^{*}}$
}

\begin{abstract}
Background: Subarachnoid hemorrhage $(\mathrm{SAH})$ is a devastating disease that affects over 30,000 Americans per year. Previous animal studies have explored the therapeutic effects of deferoxamine (DFX) via its iron-chelating properties after SAH, but none have assessed the necessity of microglial/macrophage heme oxygenase-1 (HO-1 or Hmox 1 ) in DFX neuroprotection, nor has the efficacy of an intracerebroventricular (ICV) administration route been fully examined. We explored the therapeutic efficacy of systemic and ICV DFX in a SAH mouse model and its effect on microglial/macrophage HO-1.
\end{abstract}

Methods: Wild-type (WT) mice were split into the following treatment groups: SAH sham + vehicle, SAH + vehicle, SAH + intraperitoneal (IP) DFX, and SAH + ICV DFX. For each experimental group, neuronal damage, cognitive outcome, vasospasm, cerebral and hematogenous myeloid cell populations, cerebral IL-6 concentration, and mitochondrial superoxide anion production were measured. HO-1 co-localization to microglia was measured using confocal images. Trans-wells with WT or $\mathrm{HO}_{-1}^{-1-}$ microglia and hippocampal neurons were treated with vehicle, red blood cells (RBCs), or RBCs with DFX; neuronal damage, TNF-a concentration, and microglial HO-1 expression were measured. HO-1 conditional knockouts were used to study myeloid, neuronal, and astrocyte HO-1 involvement in DFX-induced neuroprotection and cognitive recovery.

Results: DFX treatment after SAH decreased cortical damage and improved cognitive outcome after SAH yet had no effect on vasospasm; ICV DFX was most neuroprotective. ICV DFX treatment after SAH decreased cerebral IL-6 concentration and trended towards decreased mitochondrial superoxide anion production. ICV DFX treatment after $\mathrm{SAH}$ effected an increase in HO-1 co-localization to microglia. DFX treatment of WT microglia with RBCs in the trans-wells showed decreased neuronal damage; this effect was abolished in $\mathrm{HO}^{-1^{-/}}$microglia. ICV DFX after SAH decreased neuronal damage and improved cognition in Hmox fl/ffl control and Nes ${ }^{\mathrm{Cre}}$ :Hmoxf ${ }^{f / / f l}$ mice, but not $L y z M^{C r e}: H \operatorname{Hox} 7^{f l / f l}$ mice.

Conclusions: DFX neuroprotection is independent of vasospasm. ICV DFX treatment provides superior neuroprotection in a mouse model of SAH. Mechanisms of DFX neuroprotection after SAH may involve microglial/macrophage HO-1 expression. Monitoring patient HO-1 expression during DFX treatment for hemorrhagic stroke may help clinicians identify patients that are more likely to respond to treatment.

Keywords: Deferoxamine, Heme oxygenase, Immunology, Intracerebroventricular, Microglia, Subarachnoid hemorrhage, Vasospasm-independent

\footnotetext{
* Correspondence: khanafy@bidmc.harvard.edu

${ }^{1}$ Department of Neurology, Beth Israel Deaconess Medical Center, Harvard

Medical School, 3 Blackfan Circle, Boston, MA 02140, USA

${ }^{2}$ Division of Neurointensive Care Medicine, Beth Israel Deaconess Medical

Center, Harvard Medical School, 3 Blackfan Circle, Boston, MA 02140, USA
} 


\section{Background}

Over 30,000 Americans will fall victim to an aneurysmal subarachnoid hemorrhage ( $\mathrm{SAH})$ this year; nearly half of these patients will die within 6 months $[1,2]$. Of those SAH survivors, approximately $50 \%$ will develop severe cognitive and functional deficits [3, 4]. Although the majority of research in SAH has focused on the treatment of vasospasm, only nimodipine has been shown to improve outcome [5, 6]. Multiple clinical trials have demonstrated that even when vasospasm was effectively treated, morbidity and mortality were not ameliorated [7-9]. These studies suggest that neurological injury can be vasospasm-independent. Further research aimed at mitigating this heme-induced cerebral inflammatory response is required [10].

In $\mathrm{SAH}$, the heme from blood spilled into the subarachnoid space is metabolized by heme oxygenase (HO), generating excess free iron [11]. This iron is hypothesized to enable cell membrane damage via free radicals [12] with studies showing a causal relationship between unbound iron and brain injury following $\mathrm{SAH}$ [13]. Deferoxamine (DFX), an iron-chelating agent, has been shown to be neuroprotective in various hemorrhagic models via several mechanisms $[12,14]$. Previous studies using a rat model of $\mathrm{SAH}$ showed decreased brain edema, oxidative stress, and neuronal apoptosis after DFX treatment $[15,16]$. However, none of these studies assess the necessity of heme oxygenase-1 (HO-1 or Hmox1) in DFX neuroprotection nor has the efficacy of intracerebroventricular administration been fully examined. Our lab previously showed microglia to be critical in red blood cell-induced neuroinflammation [10], and most recently, we found microglial $\mathrm{HO}-1$ to be neuroprotective after SAH in a mouse model [17]. We hypothesized that microglial/macrophage HO-1 is critical for DFX neuroprotection and that intracerebroventricular administration would provide superior neuroprotection in a mouse model of SAH.

We undertook the current set of experiments to first compare the effects of systemic versus intracerebroventricular injection of DFX on neuronal damage, vasospasm, proinflammatory and oxidative biomarkers, and immune cell populations in a mouse model of $\mathrm{SAH}$; second, to see if microglial/macrophage $\mathrm{HO}-1$ is sufficient for DFX neuroprotection; and third, to compare the effects of cell-specific HO-1 knockouts on DFX neuroprotection and cognitive outcome. Our study provides a platform for the potential translation of DFX treatment into the SAH patient population.

\section{Methods}

Animal information and anesthesia

All experimental procedures were approved by the Institutional Animal Care and Use Committee
(IACUC) of Beth Israel Deaconess Medical Center (BIDMC). The facility is accredited by the Association for Assessment and Accreditation of Lab Animal Care and fully complied with all Federal, State and Local Law. Animals were housed at BIDMC and fed a standard rodent diet ad libitum with 24-h access to either water and/or hydrogel while kept on a 12-h light/12-h dark cycle. All surgical manipulations were performed under general anesthesia with ketamine $(10 \mathrm{mg} / \mathrm{kg})$ and xylazine $(4 \mathrm{mg} / \mathrm{kg})$, and buprenorphine $(50 \mu \mathrm{g} / \mathrm{kg})$ was systemically administered. All mice used were male on a C57BL/6 background (The Jackson Laboratory). Cell-specific HO-1 knockout in myeloid cells $\left(\operatorname{LyzM} M^{C r e}: H \operatorname{mox} 1^{f l f l}\right)$ and astrocytes and neurons $\left(\mathrm{Nes}^{\mathrm{Cre}}: \mathrm{Hmox} \mathrm{1}^{f l / f l}\right.$ ) was achieved as previously described by our lab [17]. All mice had similar fur color and were approximately the same size and weight. The average mouse weight was $25 \mathrm{~g}(0.025 \mathrm{~kg})$ with a weight range of $24 \mathrm{~g}(0.024 \mathrm{~kg})$ to $27 \mathrm{~g}(0.027 \mathrm{~kg})$. Wild-type (WT) mice were randomly assigned between the following four treatment groups equally: WT subarachnoid hemorrhage $(\mathrm{SAH})$ sham + intraperitoneal (IP) normal saline (NS) + intracerebroventricular (ICV) NS (SAH sham + vehicle), WT SAH + IP NS + ICV NS (SAH + vehicle), WT SAH + IP deferoxamine $(\mathrm{DFX})+\mathrm{ICV} \mathrm{NS}(\mathrm{SAH}+\mathrm{IP} \mathrm{DFX})$, and WT SAH + IP $\mathrm{NS}+\mathrm{ICV}$ DFX (SAH + ICV DFX). Lab personnel performing surgical procedures were not the same as those performing cognitive assays to allow for appropriate blinding.

\section{$\mathrm{SAH}$}

The method used to induce $\mathrm{SAH}$ has been previously tested and validated in a mouse model [18]. After the mice were anesthetized with xylazine $(10 \mathrm{mg} / \mathrm{kg})$ and ketamine $(12 \mathrm{mg} / \mathrm{kg})$, SAH was performed as previously described by our lab using a standard stereotaxic instrument set-up (KOPF Instruments, Tujunga, CA, USA) [17]. To open the skin overlying the anterior skull, a midline incision was performed. Then, a burr hole was drilled into the anterior skull, $4.5 \mathrm{~mm}$ anterior to the bregma. Sixty microliters of autologous blood from a C57BL/6 wild-type blood donor mouse was injected over a 10 -s period with a 27 -gauge needle at a $40^{\circ}$ caudal angle into the drilled burr hole. The needle was left in place for 5 min to prevent backflow of blood.

\section{Intracerebroventricular injection of deferoxamine}

After the mice were anesthetized, intracerebroventricular injection was performed using a standard stereotaxic instrument set-up (KOPF Instruments, Tujunga, CA, USA). One burr hole was drilled $0.22 \mathrm{~mm}$ posterior to the bregma, $1 \mathrm{~mm}$ lateral, and $2.25 \mathrm{~mm}$ in depth to 
enter the ventricle. On SAH POD1, $24 \mathrm{~h}$ after the induced $\mathrm{SAH}$, a single, non-repeated injection of $8 \mathrm{mg} / \mathrm{kg}$ of DFX was administered using pre-measured capillaries. Dosing was chosen based on dose-tolerance data generated by our lab (Table 1).

\section{Intraperitoneal injection of deferoxamine}

Starting on SAH POD1, 24-h after the induced SAH, the mice were given systemic injections of $200 \mathrm{mg} / \mathrm{kg}$ of DFX every morning, $30 \mathrm{~min}$ prior to cognitive test, until euthanization on SAH POD7. Dosage was chosen based on a previous publication testing systemic deferoxamine treatment in another mouse model of hemorrhagic stroke [19].

\section{TUNEL}

All in vivo imaging was taken on SAH sham or SAH post-operative day (POD) 7 due to our lab's previous publication showing SAH POD7 to have the most significant hippocampal cell damage [10]. Brain sections and HT-22 cells were stained with terminal deoxynucleotidyl transferase dUTP nick end labeling (TUNEL; Roche Life Science, Indianapolis, IN, USA). Slides were covered using Vectashield mounting medium with DAPI (Vector Laboratories, Burlingame, CA, USA) for nuclear counterstaining. HT-22 cells were counterstained with Hoechst 33258 (Sigma-Aldrich, Natick, MA, USA). Lab personnel interpreting TUNEL stains were not aware of the groups to which they were assigned.

\section{$H \& E$}

Coronal brain sections were stained with hematoxylin and eosin (H\&E) (Poly Scientific R\&D Corp., Bay Shore, NY, USA). The middle cerebral artery (MCA) lumen radius/wall thickness ratio was quantified using ImageJ software (NIH). Lab personnel interpreting H\&E stains were not aware of the groups to which they were assigned.

\section{Confocal imaging}

Eight-micrometer coronal brain sections from each experimental group were post-fixed and permeabilized,

Table 1 Intracerebroventricular deferoxamine dose-tolerance chart

\begin{tabular}{lll}
\hline ICV dose & Total mice tested & Tolerance \\
\hline $0.8 \mathrm{mg} / \mathrm{kg}(\sim 0.02 \mathrm{mg}$ per mouse) & 3 & Well tolerated \\
$8 \mathrm{mg} / \mathrm{kg}$ a ( 0.2 mg per mouse) & 3 & Well tolerated \\
$80 \mathrm{mg} / \mathrm{kg}(\sim 2 \mathrm{mg}$ per mouse) & 2 & Immediately died \\
\hline $\begin{array}{l}\text { Wild-type mice were injected with a one-time intracerebroventricular (ICV) } \\
\text { dose of deferoxamine diluted in normal saline, to test how well each dose }\end{array}$ \\
$\begin{array}{l}\text { would be tolerated } \\
\text { aThe highest dose tolerated was chosen for all experimental procedures }\end{array}$
\end{tabular}

followed by being blocked with $10 \%$ donkey serum. The sections were then stained with the following primary antibodies: goat anti-Iba1 (1:500) and rabbit anti-HO-1 (1:500) to identify HO-1 expression and HO-1 colocalization to microglia. The sections were then stained with the following secondary antibodies: donkey antigoat 488 (1:250) and donkey anti-rabbit 594 (1:250). The sections were then counterstained with nuclei marker DAPI and sealed. The sections were viewed and images were taken on a Zeiss confocal microscope. Layers of images from the most anterior to the most posterior portion were taken, and a Z-stack image was created. Image J software was used for co-localization cell counting as well as co-localization heat maps. Co-localization percentage per high-powered field for each experimental group's confocal Z-stacked images was obtained by dividing the total number of yellow-positive by the total number of DAPI-positive cells. Co-localization histograms were generated using the coloc-2 feature of ImageJ software. In brief, the program combines the green HO-1 single channel-1 saturation pixels with the red Iba- $1 /$ microglia single channel-2 saturation pixels to calculate the level at which they overlap. The $x$-axis represents channel-1 pixel intensity, while the $y$-axis represents channel-2 pixel intensity. Blue represents the lowest population frequency possible while yellow represents the highest. The lower the slope for each heat map, the more HO- 1 staining there is per Iba- $1 /$ microglia staining.

\section{ELISA}

Whole brain lysates were equally loaded onto a 96-well plate and cerebral IL-6 concentration was determined using ELISA Max Biolegend kit per manufacturer's instructions. Media from microglia-neuron trans-well experiments were equally loaded onto a 96-well plate and culture TNF- $\alpha$ concentration was determined using ELISA Max Biolegend kit per manufacturer's instructions (Biolegend, San Diego, CA, USA).

\section{Flow cytometry}

All flow cytometry acquisition was performed on a FACSCalibur (BD Biosciences, San Jose, CA, USA), and analysis was completed using FlowJo software (FlowJo, LLC, Ashland, OR, USA). Cells were isolated from whole brain or blood and re-suspended in FACS buffer $(1 \%$ bovine albumin, $2 \mathrm{mM}$ ethylenediaminetetraacetic acid (EDTA), and $0.05 \% \mathrm{NaN}_{3}$ in phosphate-buffered saline (PBS)). To block unspecific sites, the cells were first stained with CD16/32 Trustain (1:100; Biolegend, San Diego, CA, USA). The cells were then washed with FACS buffer and stained with the following fluorescenttagged antibodies: PE-Gr-1 and PeCy7-CD11b (1:100; Biolegend, San Diego, CA, USA). To identify the 
myeloid cell populations in the blood and brain, CD $45^{+}$ cells were gated off of a CD45/SSC-H dot plot. Then, using a Gr-1/CD11b dot plot, macrophages were identified as $\mathrm{CD} 11 \mathrm{~b}^{\mathrm{hi}} / \mathrm{Gr}-1^{\text {lo }}$ while neutrophils were $\mathrm{CD} 11 \mathrm{~b}^{\text {hi }} \mathrm{Gr}-\mathrm{1}^{\text {hi }}$ (Additional file 1: Figure S1). To measure the total mitochondrial superoxide anion production, whole brain cell lysates were incubated with MitoSOX red mitochondrial superoxide indicator per manufacturer's instructions $(5 \mu \mathrm{M}$; Life Technologies/ThermoFisher, Cambridge, MA, USA) and cells positive in the FL-2 channel were reported. Appropriate unstained controls for each channel were used to determine stained cell populations.

\section{Primary microglia and neuronal HT-22 cells-trans-wells}

Microglia cells were isolated from the brains of neonatal mice using the Neural Tissue Dissociation Kit (P) (Miltenyi Biotec, Cambridge, MA, USA). The resulting mixed glia culture, containing astrocytes and microglia, was cultivated in media containing macrophage-colony stimulating factor (M-CSF). After 1 week of cultivation, the microglia were collected and grown on $3-\mu \mathrm{m}$ cell culture inserts (EMD Millipore, Billerica, MA, USA). Murine hippocampal neuronal HT-22 cells were grown on sixwell plates in normal media without M-CSF. For transwell assays, the inserts with microglia were placed on top of the HT-22 neuron wells; microglia and HT-22 neuronal cells shared media during experiments. A total of $200 \mu \mathrm{l}$ of whole blood was collected from the submandibular vein of a wild-type donor mouse and placed into $10 \mathrm{ml}$ of PBS to keep the blood from clotting. The whole blood in PBS was then centrifuged at $2000 \mathrm{rpm}$ for $5 \mathrm{~min}$. The plasma, leukocyte, and platelet layers were aspirated, leaving an erythrocyte pellet. The erythrocytes were washed in an additional $10 \mathrm{ml}$ of PBS and centrifuged at $2000 \mathrm{rpm}$ for $5 \mathrm{~min}$. The supernatant was aspirated and the erythrocyte pellet was resuspended in $2 \mathrm{ml}$ of PBS; $100 \mu \mathrm{l}$ of this RBC suspension in PBS was added to the top microglia-containing chamber of the microglia-neuron trans-well; after 1-h of blood exposure, DFX $(100 \mu \mathrm{M})$ or vehicle was added to the microglia chamber, and an additional hour of incubation was completed.

\section{Western blot}

Primary microglial cell lysates were equally loaded onto a polyacrylamide gel and transferred to an immune-blot PVDF membrane (Bio-Rad, Hercules, CA, USA). Membranes were blocked with $5 \%$ milk and stained with rabbit HO-1 antibody (1:1000, Abcam, Cambridge, MA, USA) and mouse vinculin antibody (1:1000, Sigma-Aldrich, Natick, MA, USA).

\section{Morris water maze}

Cognitive performance was assessed using the Morris water maze as previously described, with minor modifications made by our lab [17]. In brief, after 7 days of acquisition, SAH sham or SAH was performed. On the day of SAH sham or SAH surgical procedure, the mice were not tested on the Morris water maze. The mice resumed testing on the Morris water maze on POD1. The mice to be treated with DFX were then either given daily IP DFX injections starting on POD1 and ending on POD7 or a one-time ICV injection of DFX on POD1. Additionally, mice that received daily IP DFX injections also got a one-time ICV injection of NS on POD1, and the mice that received a one-time ICV DFX injection also got daily IP NS injections from POD1 to POD7. SAH sham or SAH mice that were not treated with DFX, each received daily IP NS from POD1 to POD7 and a one-time injection of ICV NS on POD1 (Table 2). Spatial memory testing, measured by time to reach goal platform and consisting of 1-trial in the morning per animal per day, was started on SAH POD1 and continued for 7-days. On SAH POD4, the goal platform was moved to the opposite side of the maze (spatial reversal), while visual cue locations were unchanged. An investigator blinded to treatment groups performed the maze procedures.

\section{Statistical analysis}

Multiple experimental groups were compared using repeated-measures two-way ANOVA with Bonferroni's post hoc test for in vivo TUNEL staining and HO-1/Iba1 co-localization of multiple brain regions, and the results are presented as the mean \pm SD (GraphPad Prism). Morris water maze data was presented as the mean \pm SEM (GraphPad Prism) and analyzed using repeatedmeasures two-way ANOVA with Bonferroni's post hoc test. For all other statistical comparisons, multiple experimental groups were compared using one-way ANOVA with Bonferroni's post hoc test, and the results are presented as the mean \pm SD (GraphPad Prism). Differences were considered significant at $P<0.05$.

\section{Study approval}

All procedures involving animals were approved by the IACUC and the Radiation Safety Office (RSO) of Beth Israel Deaconess Medical Center.

\section{Results}

Intracerebroventricular deferoxamine injection dose-tolerance in wild-type mice

In order to determine the dose of DFX to be injected into the intracerebroventricular (ICV) space, a dosetolerance chart was generated using WT mice (Table 1). Since $8 \mathrm{mg} / \mathrm{kg}$ was the highest dose tested that was well 
Table 2 Wild-type experimental mouse groups

\begin{tabular}{lll}
\hline Mouse group & Abbreviation & Explanation \\
\hline $\begin{array}{l}\text { WT SAH sham } \\
+ \text { IP NS } \\
+ \text { ICV NS }\end{array}$ & $\begin{array}{l}\text { SAH sham } \\
+ \text { vehicle }\end{array}$ & $\begin{array}{l}\text { Mice received subarachnoid hemorrhage (SAH), sham surgical procedure, daily } \\
\text { intraperoteneal (IP) injections of normal saline (NS) starting on post-operative } \\
\text { day (POD) } 1 \text { and ending on POD7, and a one-time intracerebroventricular } \\
(\text { ICV) injection of NS on POD1. }\end{array}$ \\
$\begin{array}{l}\text { WT SAH } \\
+ \text { IP NS } \\
+ \text { ICV NS }\end{array}$ & $\begin{array}{l}\text { Mice received SAH surgical procedure, daily IP injections of NS starting on } \\
\text { POD1 and ending on POD7, and a one-time ICV injection of NS on POD1. }\end{array}$ \\
$\begin{array}{l}\text { WT SAH } \\
+ \text { IP DFX }\end{array}$ & SAH & $\begin{array}{l}\text { Mice received SAH surgical procedure, daily IP injections of deferoxamine } \\
\text { I ICV NS }\end{array}$ \\
$\begin{array}{l}\text { WT SAH } \\
+ \text { IP NS }\end{array}$ & Of NS on POD1. \\
+ ICV DFX & SAH DFX & Mice received SAH surgical procedure, daily IP injections of NS starting on \\
\hline
\end{tabular}

Wild-type (WT) mice were randomly assigned between the four treatment groups listed in the table. Each mouse was exposed to all surgical procedures and injections as specified in the explanation. The abbreviation listed in the table was used throughout the results including figures and figure legends for simplicity.

tolerated by the mice, this dose was chosen for further experimental procedures.

\section{Degree of deferoxamine neuroprotection and cognitive improvement after $\mathrm{SAH}$ depends on drug administration route and is vasospasm-independent}

All mice used had similar size and weight and appeared otherwise healthy prior to any surgical procedure. The WT mice were randomly assigned between the following four treatment groups: subarachnoid hemorrhage (SAH) sham + vehicle, SAH + vehicle, SAH + intraperoteneal (IP) DFX, and SAH + ICV DFX (Table 2). Neuronal damage and vasospasm were assessed for all of the treatment groups on POD7, based on our previous work [10]; cognitive outcome was assessed on POD1-7 using the Morris water maze (Fig. 1a-g). The $\mathrm{SAH}+$ vehicle mice had significantly increased cortical and hippocampal cellular damage compared to the SAH sham + vehicle mice, while the SAH + IP DFX mice and SAH + ICV DFX mice had markedly decreased cortical and hippocampal damage as compared to the SAH mice (ANOVA $P<0.05 ; P<0.05$ between groups; $n=5$; Fig. $1 \mathrm{~b}, \mathrm{c})$. The one-time ICV DFX injection decreased cortical and hippocampal damage to a greater extent than daily IP DFX injections $(P<0.05$ versus SAH + IP DFX; Fig. 1b, c). Differences in cognitive outcome arose between the treatment groups on POD4, 5, and 7. The SAH + ICV DFX treatment group resulted in better cognitive performance than the SAH + vehicle and SAH + IP DFX groups on POD4 and the $\mathrm{SAH}+$ vehicle group on POD5. Additionally, both DFX treatment groups after $\mathrm{SAH}$ improved cognitive function when compared to the SAH + vehicle group on POD7 (ANOVA $P<0.05 ; P<0.05$ between groups; $n=5$; Fig. $1 \mathrm{~d}$ ). Although the $\mathrm{SAH}+$ group had a significantly lower lumen radius to wall thickness (LR/WT) of the middle cerebral artery (MCA) than the SAH sham + vehicle group, DFX treatment had no effect on this SAH-induced MCA vasospasm (ANOVA $P<0.05 ; P<0.05$ SAH sham + vehicle versus $\mathrm{SAH}+$ vehicle; $n=5$; Fig. $1 \mathrm{f}, \mathrm{g}$ ).

Next, we determined whether or not DFX had an effect on cerebral and hematogenous myeloid cell populations; it did not ( $n=4$; Fig. $2 \mathrm{a}, \mathrm{b})$. Subsequently, we measured the effects of DFX on cerebral inflammatory milieu after SAH on POD7 by quantifying interleukin (IL)-6 and mitochondrial superoxide anion in whole brain lysates. In the SAH + vehicle group, cerebral IL-6 production was increased as compared to control (ANOVA $P<0.05 ; P<0.05$ versus $\mathrm{SAH}$ sham + vehicle; $n=4$; Fig. 2c); ICV DFX treatment markedly decreased the concentration of cerebral IL-6 after SAH while IP DFX did not $(P<0.05$ versus $\mathrm{SAH}+$ vehicle; $n=4$; Fig. 2c). Additionally, the SAH + vehicle group had increased mitochondrial superoxide anion production as compared to the control (ANOVA $P<0.05 ; P<0.05$ versus SAH sham + vehicle; $n=4$; Fig. $2 d$, e), and while not statistically significant, there was a trend towards decreased mitochondrial superoxide anion in the SAH + ICV DFX treatment group as compared to the $\mathrm{SAH}+$ vehicle group ( $n=4$; Fig. 2 d, e).

\section{Microglial HO-1 is sufficient for deferoxamine neuroprotection in an in vitro model}

To determine if DFX treatment of microglia was sufficient to reduce neuronal damage, we performed in vitro trans-well assays with WT microglia and hippocampal neuronal HT-22 cells. WT microglia incubated with red blood cells (RBCs) for $2 \mathrm{~h}$ demonstrated marked neuronal damage by the trans-well assay (ANOVA $P<0.05$; $P<0.05$ versus control; $n=3$; Fig. $3 \mathrm{a}, \mathrm{b})$. Additionally, there was a trend towards increased TNF- $\alpha$ production in the trans-well assays incubated with RBCs (ANOVA 


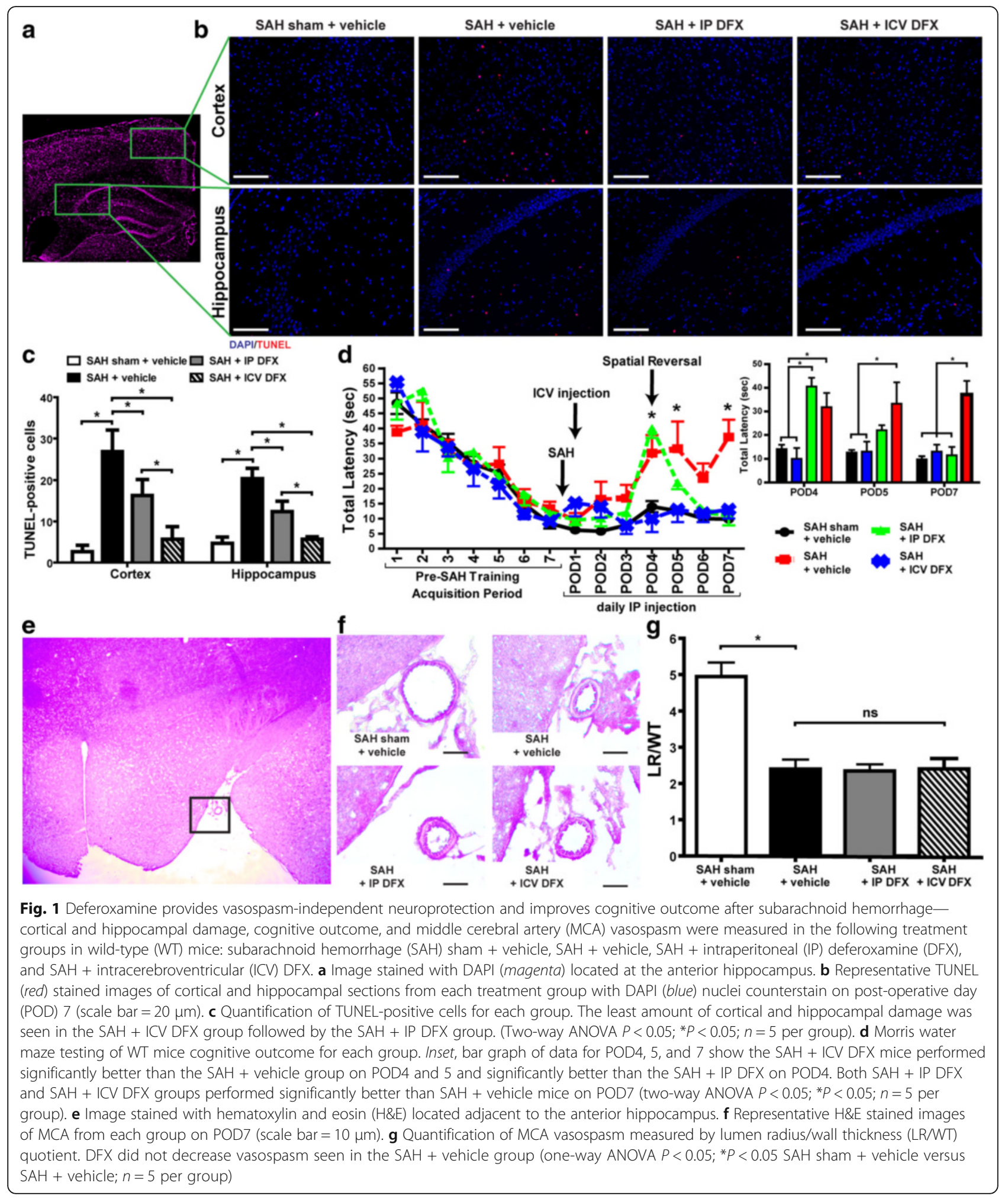

$P<0.05 ; n=3$; Fig. 3b). RBC-induced neuronal damage was significantly reduced when DFX was added $1 \mathrm{~h}$ after $\mathrm{RBC}$ exposure began, for a total RBC exposure of $2 \mathrm{~h}$ $(P<0.05$ versus $\mathrm{RBC}$ only exposure; $n=3$; Fig. $3 \mathrm{a}, \mathrm{b})$.
Further, there was a trend towards decreased TNF- $\alpha$ production in the trans-well assays treated with DFX after RBC exposure ( $n=3$; Fig. $3 b$ ). To determine if the HO-1 pathway in microglia was involved, we repeated the trans- 
a
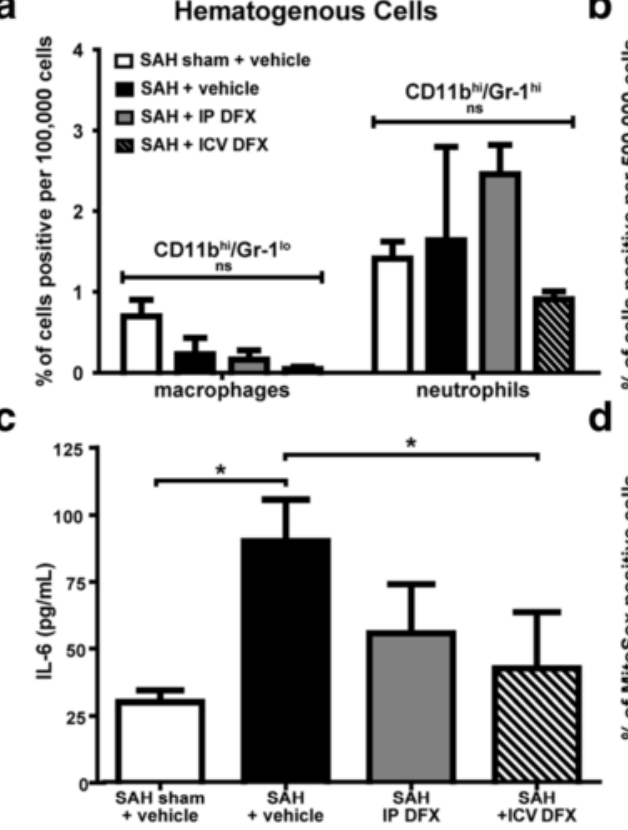

$\mathbf{e}$
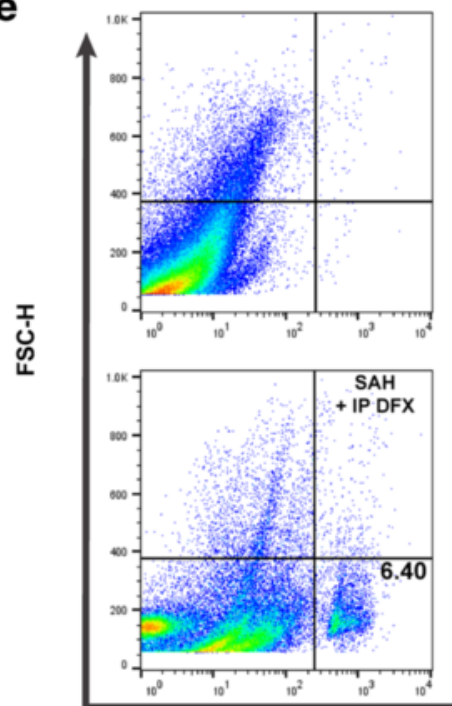

b
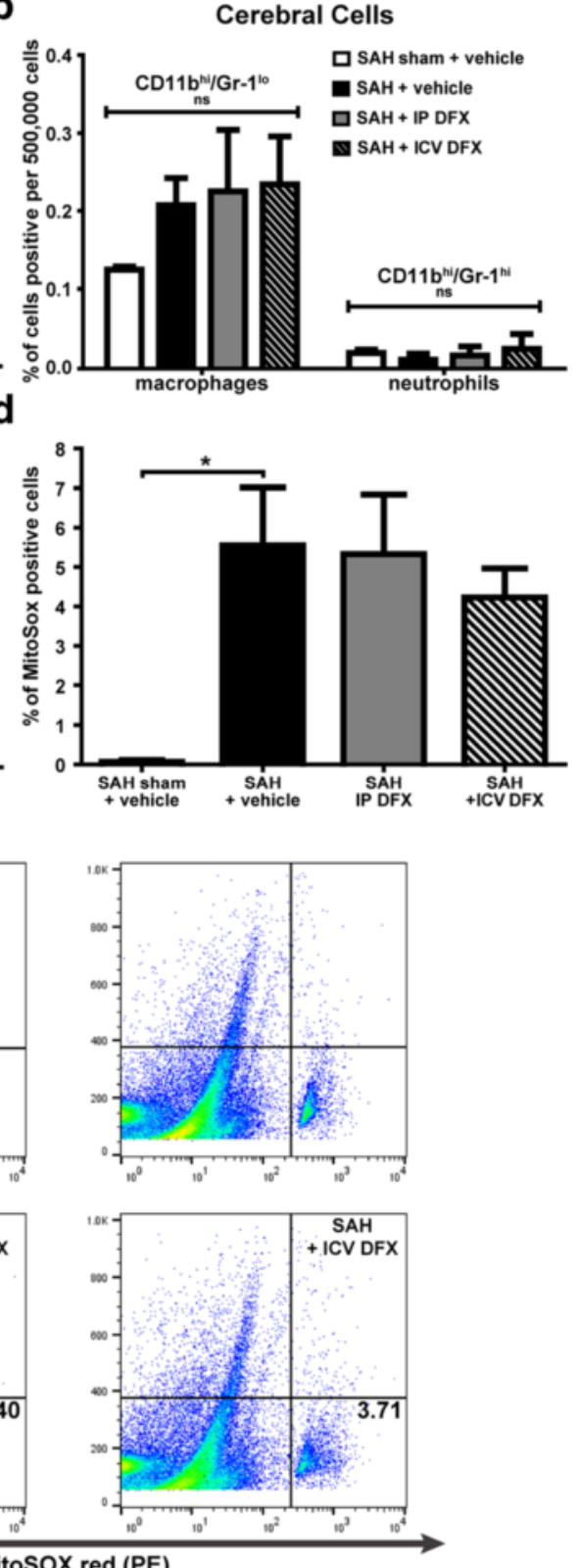

Fig. 2 ICV DFX reduces cerebral inflammatory milieu after SAH—-hematogenous and cerebral myeloid cell populations, cerebral IL-6 concentration, and cerebral mitochondrial superoxide anion were measured in the following treatment groups on POD7 in WT mice: SAH sham + vehicle, SAH + vehicle, SAH + IP DFX, and SAH + ICV DFX. a Flow cytometry of hematogenous cell populations show no significant change between any of the groups (one-way ANOVA; $n=4$ per group). $\mathbf{b}$ Flow cytometry of cerebral myeloid cell populations show a trend towards increase in the microglia/ macrophage populations of the SAH + vehicle group versus the SAH sham + vehicle group; but no significant changes between any of the other groups (one-way ANOVA; $n=4$ per group). c Cerebral IL-6 concentration as measured by ELISA was significantly increased in the SAH + vehicle group ( ${ }^{*} P<0.05$ versus the SAH sham + vehicle group) and markedly decreased in the SAH + ICV DFX group $\left({ }^{*} P<0.05\right.$ versus the SAH + vehicle group) (one-way ANOVA $P<0.05 ; n=4$ per group). $\mathbf{d}$ Cerebral mitochondrial superoxide anion (MitoSox) positive cells measured by flow cytometry did not show significant decrease in the SAH + ICV DFX group versus the SAH + vehicle group and the SAH + IP DFX group (one-way ANOVA $P<0.05 ; n=4$ per group). e Representative flow cytometry dot plots from each group. The Q3 percentage (shown) represents the percentage of cells positive for MitoSOX red

well experiment using $\mathrm{HO}-1^{-1-}$ microglia. In the transwell assays with $\mathrm{HO}-1^{-1-}$ microglia, neuronal damage and TNF- $\alpha$ production was notably increased in trans-wells exposed to RBCs for $2 \mathrm{~h}$ (ANOVA $P<0.05 ; P<0.05$ versus control; $n=3$; Fig. 3c, d). But unlike the WT microglia trans-wells, RBC-induced neuronal damage was not significantly reduced in neurons underlying $\mathrm{HO}-1^{-/-}$ microglia when DFX was added ( $n=3$; Fig. $3 \mathrm{c}$, d). Further, 
TNF- $\alpha$ concentrations remained markedly elevated in assays with $\mathrm{HO}-1^{-1-}$ microglia after DFX addition to the RBC-treated trans-wells ( $n=3$; Fig. 3d).

Next, we sought to determine why the loss of microglial HO-1 diminished the neuroprotective effects of DFX. First, we measured the HO-1 protein expression in primary microglial lysates exposed to vehicle, RBCs, or $\mathrm{RBCs}$ with DFX. There was increased HO-1 protein expression in the microglia treated with RBCs and DFX as compared to vehicle (ANOVA $P<0.05 ; P<0.05$ versus control; $n=3$; Fig. 3e, f).
Intracerebroventricular deferoxamine increases in vivo microglia and HO-1 co-localization

We wanted to validate the results we observed in our in vitro model, in vivo. That is, we wanted to examine whether ICV DFX increased microglial HO-1 expression in our in vivo SAH model. To see if DFX caused an increase in microglia and HO-1 co-localization, we took Z-stacked confocal images of brain sections adjacent to the anterior hippocampus, stained for microglia (Iba-1 positive) and HO-1 of all four of our in vivo experimental groups (Table 2). HO-1 co-localization to microglial

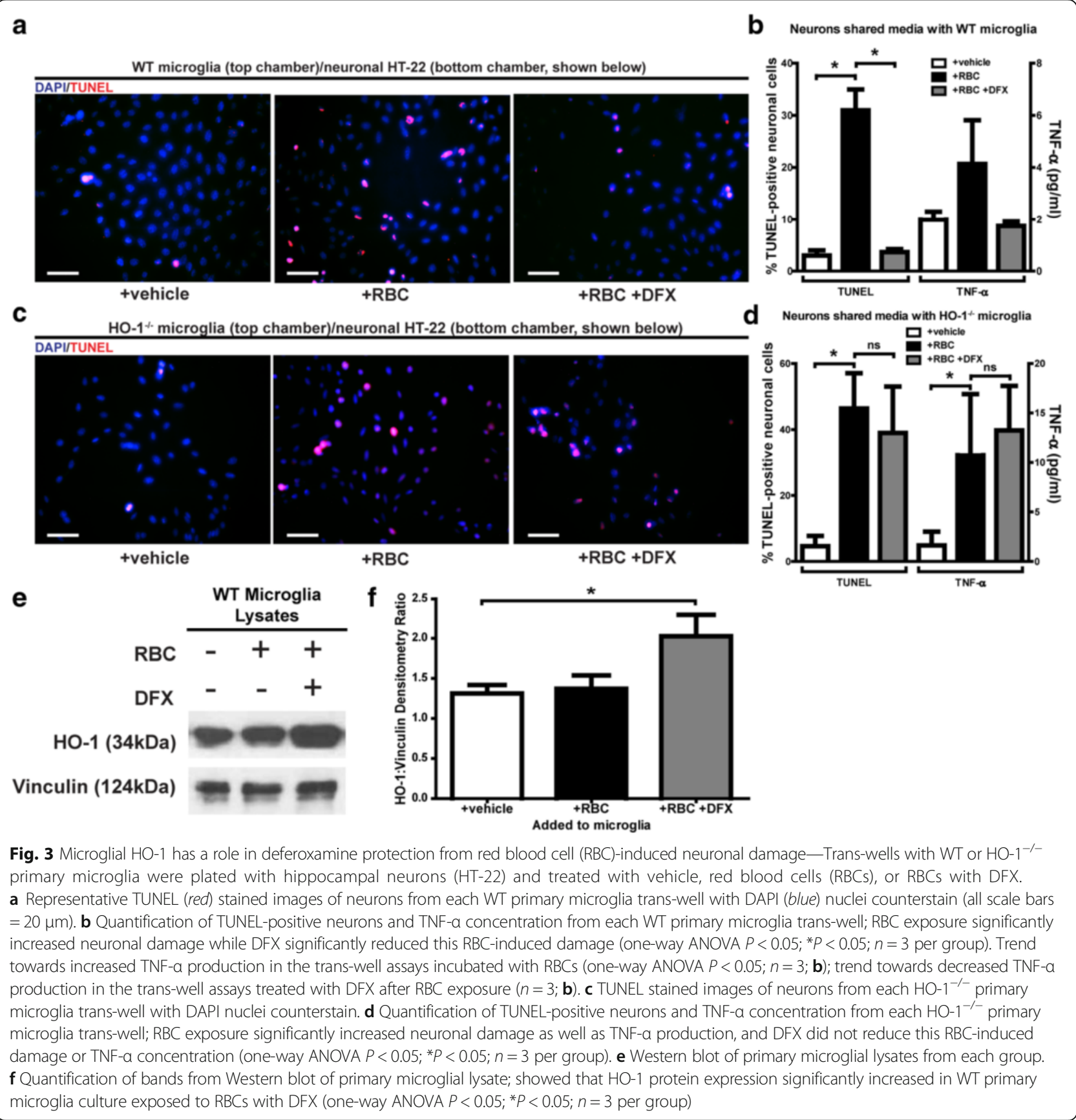


cells on these in vivo sections from lowest to highest was as follows: SAH sham + vehicle, SAH + vehicle, $\mathrm{SAH}+\mathrm{IP}$ DFX, and SAH + ICV DFX (ANOVA $P<0.05$; $P<0.05$ between groups; $n=3$; Fig. $4 \mathrm{a}-\mathrm{c})$.

\section{Microglial/macrophage HO-1 is critical to intracerebroven- tricular deferoxamine neuroprotection and cognitive improvement after $\mathrm{SAH}$}

We performed SAH on $L y z M^{C r e}: H m o x f^{f l / f l}$ mice lacking microglial, neutrophil, and all other myeloid HO-1 as well as in $\mathrm{NeS}^{\mathrm{Cre}}: \mathrm{Hmox}_{1} \mathrm{f}^{f l f l}$ mice lacking neuronal and astrocyte HO-1 and Hmoxilflfl control mice and measured the amount of HO-1 co-localization to microglia in each. $L y z M^{C r e}: H m o x f^{f l / f l}$ SAH mice showed the least HO-1/Iba-1 co-localization percentage in both the cortex and hippocampus as compared to Hmoxi $P^{f l f l}$ and $\mathrm{NeS}^{\mathrm{Cre}}: \mathrm{Hmox} \mathrm{f}^{f l / f l} \mathrm{SAH}$ mice on POD7 (two-way ANOVA $P<0.05 ; P<0.05$ between groups; $n=4$; Fig. $5 \mathrm{a}, \mathrm{b})$. We then performed SAH and subsequent ICV DFX treatment on $L y z M^{C r e}: H \operatorname{mox} 1^{f l / f l}, \quad N e S^{C r e}: \operatorname{Hmoxp}^{f l / f l}$, and Hmoxi $1^{f l f l}$ control mice. ICV DFX-treated $L y z M^{C r e}: H-$ $\operatorname{mox} \mathrm{f}^{f l / f l}$ mice after SAH showed significant cortical and hippocampal damage on POD7 as compared to ICV DFX treated Hmoxf flffl SAH controls, while ICV DFX treated Nes ${ }^{\mathrm{Cre}}: \mathrm{Hmox}_{1}{ }^{\text {fl/fl }}$ mice after SAH did not (ANOVA $P<0.05 ; P<0.05$ between groups; $n=4$; Fig. 5 c, d). Cognitive protection of ICV DFX after SAH was tested on Hmoxi $1^{f l f l}, L y z M^{C r e}: H \operatorname{mox} 1^{f l f l}$, and $\mathrm{Nes}^{\mathrm{Cre}}: \mathrm{H}-$ $\operatorname{mox} f^{f l / f l}$ mice. The $L y z M^{C r e}: H \operatorname{mox} f^{f l f l}$ mice performed markedly worse than the Hmox $1^{f l f l}$ control mice (ANOVA $P<0.05 ; P<0.05$ between groups for POD5 and $7 ; n=4$ Fig. 5e) while $N e s^{C r e}: H m o x 1^{f l / f l}$ mice performed just as well as Hmoxi $1^{f l f l}$ control mice and significantly better than $L y z M^{C r e}: H \operatorname{mox} \mathrm{P}^{f l / f l}$ mice $(P<0.05$; $P<0.05$ between groups for POD5 and 7; $n=4$ Fig. 5e).

\section{Discussion}

In a mouse model of SAH, we found that DFX exerted neuroprotective effects by non-canonical mechanisms. (1) DFX improved cognitive outcomes and reduced cerebral damage, independent of vasospasm. (2) ICV DFX was the most neuroprotective. (3) ICV DFX decreased neuroinflammatory markers. (4) Microglial HO-1 is sufficient for DFX neuroprotection in an in vitro model of blood-induced inflammation. (5) ICV DFX neuroprotection and cognitive improvement is dependent on microglial/macrophage HO-1.

The iron-chelating agent, DFX, has been tested for therapeutic use in many animal neurological disease models including Huntington's disease [20], traumatic brain injury [21-23], cerebral ischemia [24-26], and hemorrhagic stroke among others. DFX has been extensively studied in animal models of intraventricular hemorrhage (IVH) and intracerebral hemorrhage (ICH). In IVH animal models,
DFX reduced ventricular enlargement, brain damage, and markers of post-hemorrhagic chronic hydrocephalus [27-31]. In ICH animal models, DFX has been shown to reduce brain damage [32-37], decrease neuroinflammation [34, 38-40], and improve cognitive outcome $[38,41]$. Further, DFX was shown to reduce DNA damage [37, 40], oxidative stress [32, 33, 38], neuronal hemoglobin expression [42], and autophagy markers [43], following ICH. Additionally, in a germinal matrix hemorrhage model of neonatal rats, DFX reduced brain damage, ventricular dilation, and improved cognitive outcome [44].

Although DFX treatment has also been studied in SAH animal models, experiments using DFX treatment specifically in a mouse model of SAH are lacking. In rat models of SAH, DFX has been shown to decrease overall mortality, edema, oxidative stress, and neuronal death $[15,16]$. Additionally, DFX treatment after SAH has been shown to decrease cortical apoptotic markers [16] and reduce markers of brainstem damage in rats [45], as well as reduce lipid peroxidation markers and improve sodium-potassium ATPase activity in guinea pigs [46]. Our study looked to further elucidate the mechanisms of DFX-induced neuroprotection in a mouse model of SAH.

In our current study, administration of DFX after induction of SAH in our mouse model was effective in reducing the cerebral inflammatory response. DFX administered via two different routes, reduced cortical and hippocampal damage after SAH on POD7; the greatest reduction was seen with ICV DFX, followed by IP DFX (Fig. 1b, c). Further, both IP and ICV DFX treatment improved cognitive outcome during a later phase of $\mathrm{SAH}$ POD7, but only ICV DFX treated mice showed early improvement on POD4 and 5. Although DFX administration effectively reduced brain damage (Fig. 1b, c) and improved cognitive outcome (Fig. 1d) after SAH, it had no effect on vasospasm (Fig. 1f, g). These results were interesting for two reasons. First, the IP dose of DFX is 25 -fold greater than the ICV dose, and yet the ICV dose showed more neuroprotection and earlier cognitive improvement. A potential explanation is that ICV administration allows for proximity to the heme burden, while IP-administered DFX has to effectively cross the blood brain barrier. Second, DFX provided cerebral protection and improved cognition after SAH independent of any effect on vasospasm, similar to previous studies that showed DFX treatment had no effect on vascular response after SAH $[47,48]$. Vasospasm-independent cerebral protection provided by DFX is not surprising when one considers recent clinical trials that effectively treated vasospasm but did not improve morbidity or mortality after SAH $[7,8]$.

DFX has been previously shown to have antiinflammatory effects in hemorrhagic stroke [14]. We 

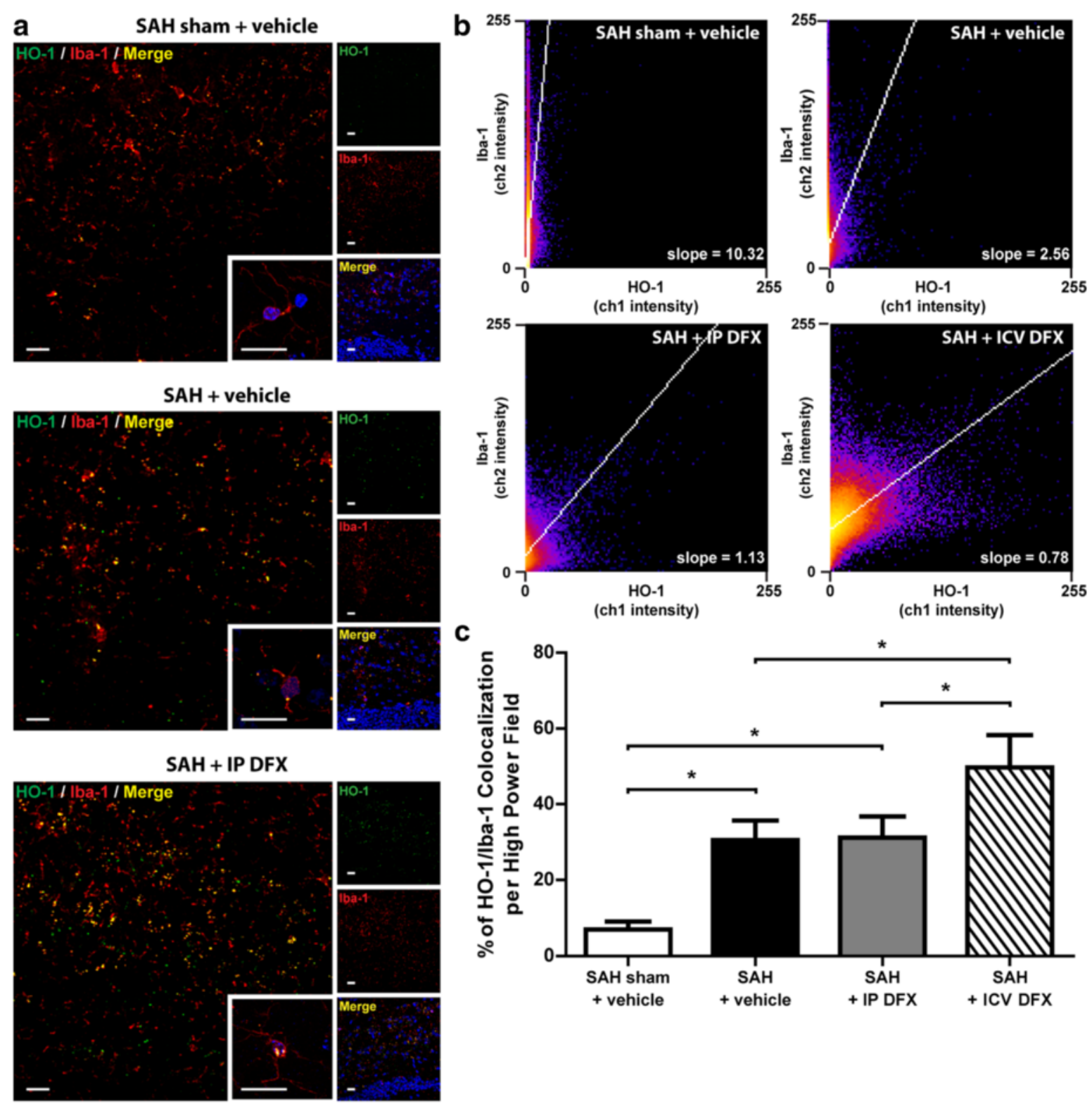

SAH + ICV DFX

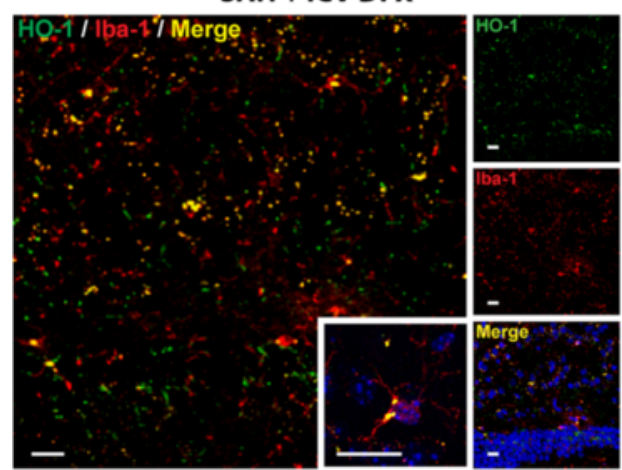

Fig. 4 (See legend on next page.) 


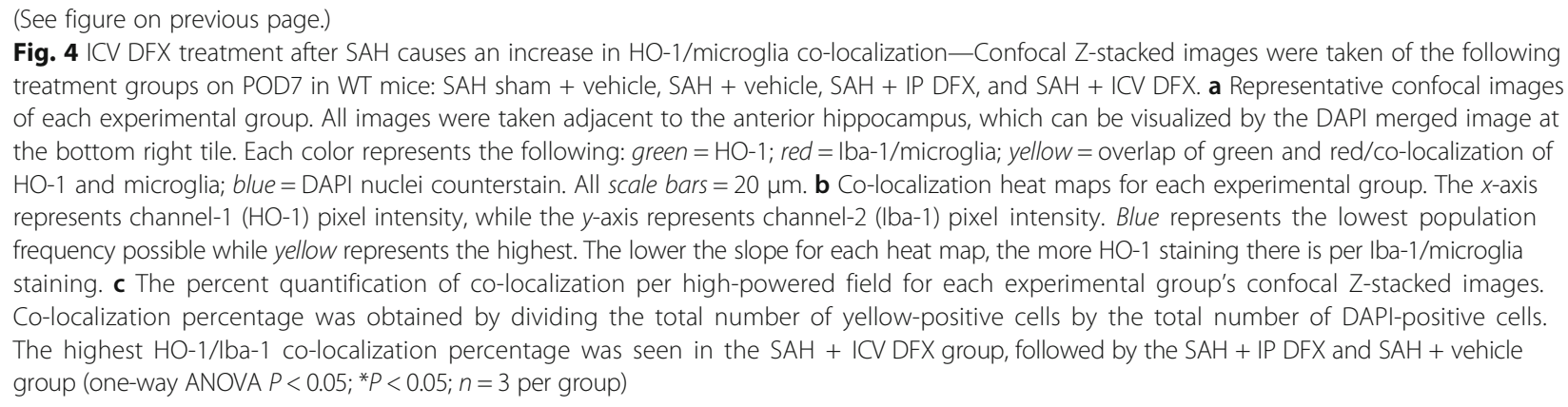

investigated whether these anti-inflammatory effects might be partly mediated by changes in immune cell populations, cerebral IL-6 concentration, or mitochondrial superoxide anion production. The $\mathrm{SAH}+$ vehicle group showed an upward trend in the cerebral microglial/macrophage cell population as compared to the SAH sham + vehicle group, but DFX did not significantly reduce this increase. Cerebral neutrophils and hematogenous populations of macrophages and neutrophils remained unchanged with DFX administration (Fig. 2a, b). Further, SAH caused a significant increase in both cerebral IL- 6 concentrations and mitochondrial superoxide production as compared to sham; in the ICV DFX-treated group, cerebral IL-6 concentrations were reduced and a trend towards decreased reduction in mitochondrial superoxide production was present (Fig. 2c-e). These results indicate that ICV DFX may partially exert protective effects not by changing the total number of microglia/macrophage cells, but instead via modulation of the pro-inflammatory mechanics of these cells, while systemic DFX injection does not.

We investigated whether DFX neuroprotection was dependent on microglia using a microglia-neuron transwell assay. These assays revealed that DFX offered protection against red blood cell (RBC) induced neuronal damage, even when DFX was added to microglia after RBC exposure had already begun (Fig. 3a, b). When we repeated these trans-well assays with $\mathrm{HO}-1^{-1-}$ microglia, DFX offered no neuroprotection (Fig. 3c, d). Additionally, we found that DFX treatment increased the protein expression of HO-1 in primary microglial culture (Fig. 3e, f). These results suggest that microglial HO-1 is critical to the mechanism of DFX neuroprotection, possibly, in part, by facilitating the increased expression of microglial HO-1. Our lab has previously shown that administration of carbon monoxide $(\mathrm{CO})$ rescues the neuronal injury seen in co-cultures with $\mathrm{HO}-1^{-1-}$ microglia [17]. This indicates that the neuroprotective product of heme breakdown via microglial $\mathrm{HO}-1$ in the context of microglia-neuron co-cultures is CO. Since this current work shows microglial HO-1 to be increased following DFX treatment, it is likely that increased $\mathrm{CO}$ production may be involved. Additionally, DFX would chelate the excess iron from heme breakdown, potentially leading to synergistic benefits produced by DFX administration: increased $\mathrm{CO}$ protection and decreased iron toxicity.

When we looked at confocal images of all of our experimental groups, we found that SAH markedly increased the co-localization of microglia and HO-1 compared to sham. Further, we found that ICV DFX treatment affected a significant increase in HO-1 expression within microglia while IP DFX did not (Fig. $4 \mathrm{a}-\mathrm{c}$ ). Because these results demonstrated that ICV DFX most effectively increased microglial HO-1 expression in vivo, we next sought to ascertain the necessity of microglial HO-1 for ICV DFX neuroprotection. Mice lacking myeloid HO-1 ( LyzM $^{C r e}:$ Hmox $P^{f l f l}$ ) and mice lacking neuronal and astrocyte HO-1 (NeS $\left.{ }^{C r e}: \mathrm{Hmox}^{\mathrm{fl} / f \mathrm{l}}\right)$ were exposed to SAH and then treated with ICV DFX. Interestingly, ICV DFX treatment after SAH protected the $N e{ }^{C r e}: H \operatorname{mox} f^{f l / f l}$ mice similarly to the Hmoxi ${ }^{f l / f l}$. Conversely, $L y z M^{C r e}: H m o x P^{f l f l}$ mice showed significantly more neuronal damage and cognitive dysfunction compared to Hmox $1^{f l f l}$ mice (Fig. $5 \mathrm{c}-\mathrm{e}$ ). This, together with the in vitro data, supported the hypothesis that myeloid HO-1, but not astrocyte or neuronal HO-1, was critical for ICV DFX to reduce brain damage and improve cognition after SAH.

It is still not completely clear why the lack of myeloid HO-1 would suppress DFX neuroprotection in vivo, but we speculate that the DFX mediated increase in myeloid HO-1 cannot occur in the myeloid HO-1 knockout $\left(L y z M^{C r e}: H m o x 1^{f l f l}\right)$ mice. Without the increased myeloid HO-1 expression, the subsequent increase in neuroprotective $\mathrm{CO}$ production would be absent. In our previous work, we showed that the neuronal damage and cognitive dysfunction seen in $L y z M^{C r e}: H \operatorname{mox} f^{f l f l}$ mice could be saved by administering external $\mathrm{CO}$, showing that $\mathrm{CO}$ was the neuroprotective byproduct of myeloid $\mathrm{HO}-1$ heme breakdown [17]. Since our current in vitro data suggests that microglial HO-1 is crucial for DFX neuroprotection, it is possible that increased myeloid HO-1 expression in vivo, due to DFX administration, could 


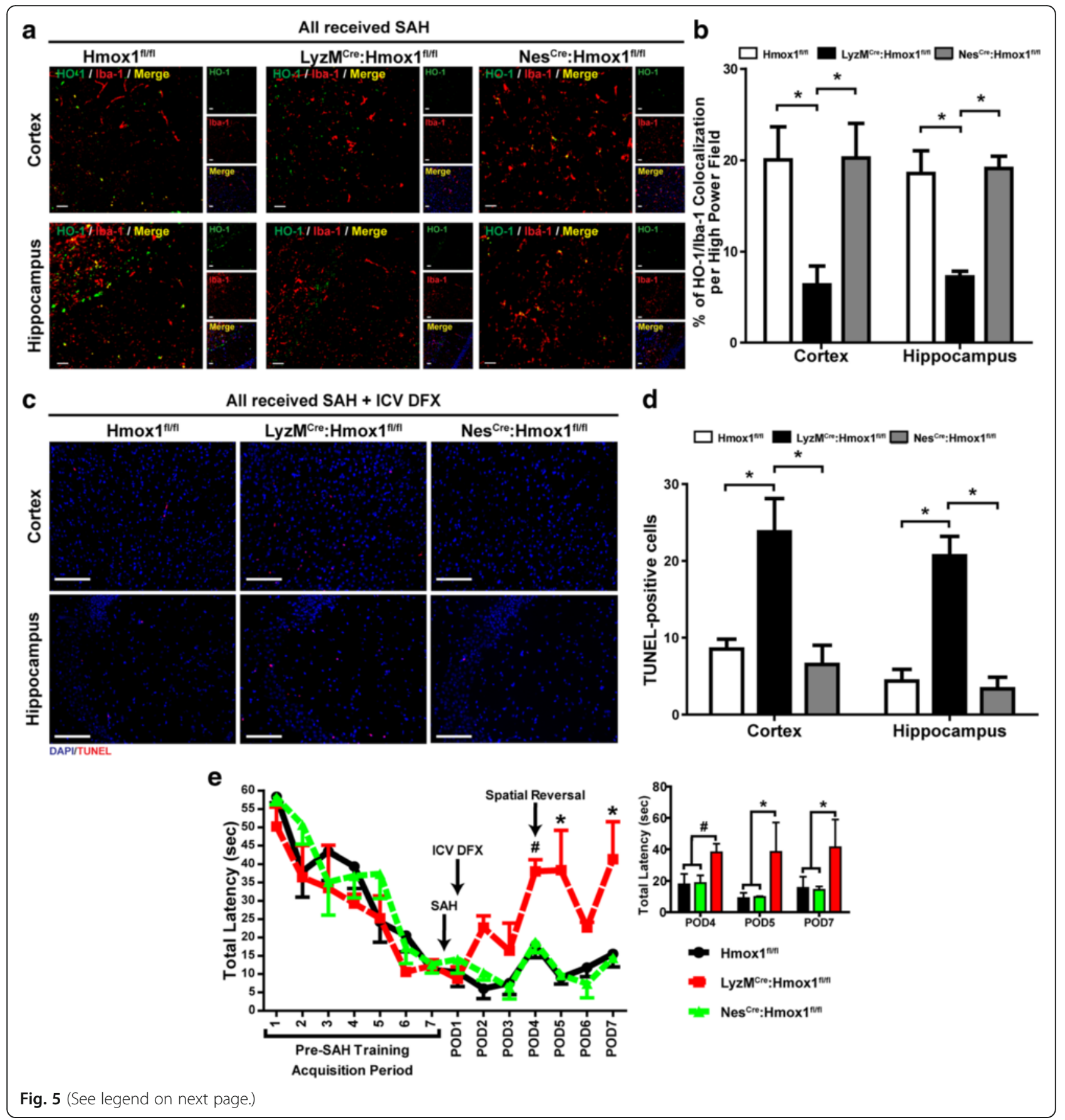


(See figure on previous page.)

Fig. 5 Macrophage/microglial HO-1 is critical to ICV DFX neuroprotection and improvement in cognitive outcome after SAH-Cortical and hippocampal damage as well as cognitive outcome were measured after SAH induction and ICV DFX treatment in the following HO-1 conditional knockouts: Hmoxi $1^{\mathrm{fl} / \mathrm{fl}}$, LyzM ${ }^{\mathrm{Cr} e}: \mathrm{Hmox}^{\mathrm{fl} / \mathrm{fl}}$, and $\mathrm{Nes}^{\mathrm{Cre}}: \mathrm{Hmox} 1^{\mathrm{fl} / \mathrm{fl}}$. a Representative confocal images of cortical and hippocampus sections for each genotype after SAH on POD7. Each color represents the following: green = HO-1; red = Iba-1/microglia; yellow = overlap of green and red/co-localization of HO-1 and microglia; blue = DAPI nuclei counterstain. All scale bars $=20 \mu \mathrm{m}$. b The percent quantification of co-localization per high-powered field for each genotype's Z-stacked images. Co-localization percentage was obtained by dividing the total number of yellow-positive cells by the total number of DAPI-positive cells. LyzM ${ }^{\mathrm{Cre}}: \mathrm{Hmox}^{\mathrm{fl} / \mathrm{fl} \mathrm{l}} \mathrm{SAH}$ mice showed the least HO-1//ba-1 co-localization percentage in both the cortex and hippocampus as compared to Hmox1 $1^{\mathrm{fl} / \mathrm{fl}}$ and $\mathrm{Nes}{ }^{\mathrm{Cre}}$ :Hmox ${ }^{\mathrm{fl} / \mathrm{fl}} \mathrm{SAH}$ mice (two-way ANOVA $P<0.05 ;{ }^{*} P<0.05 ; n=4$ per group). c TUNEL (red) stained images of cortical and hippocampal sections from each group with DAPI (blue) nuclei counterstain on POD7 (scale bar $=20 \mu \mathrm{m}$ ). $\mathbf{d}$ Quantification of TUNEL-positive cells from each treated genotype. Both Hmox $1^{\text {fl/fl }}$ and $\mathrm{Nes}^{\mathrm{Cre}}$ :Hmox ${ }^{\mathrm{fl} / \mathrm{fl}}$ SAH mice showed significantly less cortical and hippocampal damage than LyzM ${ }^{\mathrm{Cre}}: \mathrm{Hmox}_{1}{ }^{\mathrm{fl} / \mathrm{fl}} \mathrm{SAH}$ mice when treated with ICV DFX. (Two-way ANOVA $P<0.05$; ${ }^{*} P<0.05$ between groups for cortical damage and ${ }^{*} P<0.05$ between groups for hippocampal damage; $n=4$ per group). e Morris water maze testing of HO-1 conditional knockout cognition after SAH induction and ICV DFX treatment. Inset, bar graph of data for POD4, 5, and 7 shows both Hmox $1^{\mathrm{fl} / \mathrm{fl}}$ and $\mathrm{Nes}^{\mathrm{Cre}}$ :Hmox $1^{\mathrm{fl} / \mathrm{fl}}$ SAH mice performed significantly better than LyzM ${ }^{C r e}$ :Hmox ${ }^{\text {fl/fl }}$ SAH mice on POD5 and 7 when treated with ICV DFX, with a similar trend on POD4. (Two-way ANOVA $P<0.05 ;: P=0.07$ between groups on POD4; ${ }^{*} P<0.05$ between groups on POD5 and $7 ; n=4$ per group)

cause increased $\mathrm{CO}$ production and thus result in better protection. Further experimentation would be necessary to test this theory.

We chose the anterior circulation model [18] over the endovascular perforation model and acknowledge that there are limitations; however, we felt that the strengths of the anterior circulation model outweighed the weaknesses. In the anterior circulation model, the increase in intracranial pressure is less severe. Additionally, blood entering the subarachnoid space of a mouse in this method would be that of a donor mouse. On the other hand, the endovascular perforation method better approximates the intracranial pressure crises that can occur in SAH patients.

However, the anterior circulation model has a number of advantages over the endovascular perforation method. First, the amount of blood $(60 \mu \mathrm{l})$ injected into each mouse, and the resultant increased intracranial pressure is consistent between mice. Because of this, we feel that results obtained using the anterior circulation method are better reproduced. Further, the lower mortality seen with this model is helpful when performing experiments on conditional knockouts, as well as dual injection procedures required for $\mathrm{SAH}$ and intracerebroventricular DFX. We have used the anterior circulation method in our past research and believe it to be suitable for our current research interests as well.

In stroke patients, DFX reduced serum markers of oxidative stress and increased antioxidant species [49], while in ICH patients, phase-I testing revealed DFX to be safe and well tolerated [50]. Currently, promising clinical trials investigating the use of DFX for $\mathrm{ICH}$ are underway [51]. Our research provides a platform for linear translation of DFX treatment into the human SAH population. Our data show that intracerebroventricular DFX yields the greatest neuroprotection via a mechanism that is dependent on microglial HO-1 and possibly a protective microglial polarization. Given the fact that high-grade $\mathrm{SAH}$ patients will have an external ventriculostomy drain (EVD) placed at admission, a feasibility study for the use of intracerebroventricular DFX in these patients should be explored in the future. Furthermore, monitoring patient HO-1 expression during DFX treatment for hemorrhagic stroke may help clinicians identify patients that are more likely to respond to treatment.

\section{Conclusions}

ICV DFX treatment provides superior neuroprotection in a mouse model of SAH. Our results indicate that the mechanisms by which DFX provides neuroprotection after SAH may involve microglial/macrophage HO-1 expression. Monitoring patient $\mathrm{HO}-1$ expression during DFX treatment for hemorrhagic stroke may help clinicians identify patients that are more likely to respond to treatment.

\section{Additional file}

Additional file 1: Figure S1. Flow cytometry gating method for identification of hematogenous and cerebral cells. (TIF 9440KB)

\section{Abbreviations}

BIDMC: Beth Israel Deaconess Medical Center; CO: Carbon monoxide; DFX: Deferoxamine; EDTA: Ethylenediaminetetraacetic acid; EVD: External ventriculostomy drain; Fl: Flox; H\&E: Hematoxylin and eosin; HO: Heme oxygenase; HO-1/Hmox1: Heme oxygenase-1; IACUC: Institutional Animal Care and Use Committee; ICH: Intracerebral hemorrhage; ICV: Intracerebroventricular; IL-6: Interleukin six; IP: Intraperitoneal; IVH: Intraventricular hemorrhage; LR/WT: Lumen radius/wall thickness; MCA: Middle cerebral artery; M-CSF: Macrophage-colony stimulating factor; NS: Normal saline; PBS: Phosphatebuffered saline; POD: Post-operative day; RBC: Red blood cell; SAH: Subarachnoid hemorrhage; TNF-a: Tumor necrosis factor-alpha; TUNEL: Terminal deoxynucleotidyl transferase dUTP nick end labeling; WT: Wild-type

\section{Acknowledgements}

None.

\section{Funding}

National Institute of Health Grants K08NS078048 to K.A. Hanafy and U01NS074425 to M.H. Selim. Any unique constructs, techniques, or mice described in this paper will be provided upon request. 


\section{Availability of data and materials}

All data on which the conclusions of the manuscript rely is presented in the main paper.

\section{Authors' contributions}

$\mathrm{RHL}$ and $\mathrm{RC}$ were all involved in performing the experiments, the data analysis, and the manuscript preparation and editing. MHS was involved in the manuscript editing and the data analysis. $\mathrm{KAH}$ was involved in the manuscript preparation, the data analysis, and the project design. All authors read and approved the final manuscript.

\section{Competing interests}

The authors declare that they have no competing interests.

\section{Consent for publication}

None.

\section{Ethics approval and consent to participate}

All experimental procedures were approved by the Institutional Animal Care and Use Committee (IACUC) of Beth Israel Deaconess Medical Center (BIDMC). The facility is accredited by the Association for Assessment and Accreditation of Lab Animal Care and fully complied with all Federal, State and Local Law. All procedures involving animals were approved by the IACUC and the Radiation Safety Office (RSO) of BIDMC.

\section{Disclosures}

M.H. Selim holds an IND for the use of deferoxamine mesylate in hemorrhagic stroke (IND \#77306).

\section{Received: 5 July 2016 Accepted: 2 September 2016}

\section{Published online: 13 September 2016}

\section{References}

1. Bederson JB, Connolly ES, Batjer HH, Dacey RG, Dion JE, Diringer MN, et al. Guidelines for the management of aneurysmal subarachnoid hemorrhage: a statement for healthcare professionals from a special writing group of the Stroke Council, American Heart Association. Stroke. 2009:40(3):994-1025.

2. Hop JW, Rinkel GJ, Algra A, van Gijn J. Case-fatality rates and functional outcome after subarachnoid hemorrhage: a systematic review. Stroke. 1997; 28(3):660-4.

3. Suarez JI, Tarr RW, Selman WR. Aneurysmal subarachnoid hemorrhage. N Engl J Med. 2006;354(4):387-96.

4. Suarez Il. Diagnosis and management of subarachnoid hemorrhage. Continuum (Minneap Minn). 2015;21 (5 Neurocritical Care):1263-87.

5. Allen GS, Ahn HS, Preziosi TJ, Battye R, Boone SC, Boone SC, et al. Cerebral arterial spasm - a controlled trial of nimodipine in patients with subarachnoid hemorrhage. N Engl J Med. 1983;308(11):619-24.

6. Velat GJ, Kimball MM, Mocco JD, Hoh BL. Vasospasm after aneurysmal subarachnoid hemorrhage: review of randomized controlled trials and meta-analyses in the literature. World Neurosurg. 2011;76(5):446-54.

7. Macdonald RL, Kassell NF, Mayer S, Ruefenacht D, Schmiedek P, Weidauer S, et al. Clazosentan to overcome neurological ischemia and infarction occurring after subarachnoid hemorrhage (CONSCIOUS-1): randomized, double-blind, placebo-controlled phase 2 dose-finding trial. Stroke. 2008; 39(11):3015-21.

8. Macdonald RL, Higashida RT, Keller E, Mayer SA, Molyneux A, Raabe A, et al. Clazosentan, an endothelin receptor antagonist, in patients with aneurysmal subarachnoid haemorrhage undergoing surgical clipping: a randomised, double-blind, placebo-controlled phase 3 trial (CONSCIOUS-2). Lancet Neurol. 2011;10(7):618-25.

9. Etminan N, Vergouwen MDI, llodigwe D, Macdonald RL. Effect of pharmaceutical treatment on vasospasm, delayed cerebral ischemia, and clinical outcome in patients with aneurysmal subarachnoid hemorrhage: a systematic review and meta-analysis. J Cereb Blood Flow Metab. 2011;31(6):1443-51.

10. Hanafy KA. The role of microglia and the TLR4 pathway in neuronal apoptosis and vasospasm after subarachnoid hemorrhage. J Neuroinflammation. 2013;10:83.

11. Hanafy KA, Oh J, Otterbein LE. Carbon Monoxide and the brain: time to rethink the dogma. Curr Pharm Des. 2013;19(15):2771-5.

12. Loftspring MC. Iron and early brain injury after subarachnoid hemorrhage. J Cereb Blood Flow Metab. 2010;30(11):1791-2.
13. Gomes JA, Selim M, Cotleur A, Hussain MS, Toth G, Koffman L, et al. Brain iron metabolism and brain injury following subarachnoid hemorrhage: iCeFISH-pilot (CSF iron in SAH). Neurocrit Care. 2014;21 (2):285-93.

14. Selim M. Deferoxamine mesylate: a new hope for intracerebral hemorrhage: from bench to clinical trials. Stroke. 2009;40(3 Suppl):S90-1.

15. Lee J-Y, Keep RF, He Y, Sagher O, Hua Y, Xi G. Hemoglobin and iron handling in brain after subarachnoid hemorrhage and the effect of deferoxamine on early brain injury. J Cereb Blood Flow Metab. 2010;30(11):1793-803.

16. Yu Z-Q, Jia Y, Chen G. Possible involvement of cathepsin B/D and caspase-3 in deferoxamine-related neuroprotection of early brain injury after subarachnoid haemorrhage in rats. Neuropathol Appl Neurobiol. 2014;40(3):270-83.

17. Schallner N, Pandit R, LeBlanc R, Thomas AJ, Ogilvy CS, Zuckerbraun BS, et al. Microglia regulate blood clearance in subarachnoid hemorrhage by heme oxygenase-1. J Clin Invest. 2015;125(7):2609-25.

18. Sabri M, Jeon H, Ai J, Tariq A, Shang X, Chen G, et al. Anterior circulation mouse model of subarachnoid hemorrhage. Brain Res. 2009;1295:179-85.

19. Wu H, Wu T, Xu X, Wang J, Wang J. Iron toxicity in mice with collagenaseinduced intracerebral hemorrhage. J Cereb Blood Flow Metab. 2011;31(5): 1243-50.

20. Chen J, Marks E, Lai B, Zhang Z, Duce JA, Lam LQ, et al. Iron accumulates in Huntington's disease neurons: protection by deferoxamine. PLoS One. 2013; 8(10):e77023.

21. Zhao J, Chen Z, Xi G, Keep RF, Hua Y. Deferoxamine attenuates acute hydrocephalus after traumatic brain injury in rats. Transl Stroke Res. 2014; 5(5):586-94.

22. Zhao J, Xi G, Wu G, Keep RF, Hua Y. Deferoxamine attenuated the upregulation of lipocalin-2 induced by traumatic brain injury in rats. Acta Neurochir Suppl. 2016;121:291-4.

23. Long DA, Ghosh K, Moore AN, Dixon CE, Dash PK. Deferoxamine improves spatial memory performance following experimental brain injury in rats. Brain Res. 1996;717(1-2):109-17.

24. Mu D, Chang YS, Vexler ZS, Ferriero DM. Hypoxia-inducible factor 1alpha and erythropoietin upregulation with deferoxamine salvage after neonatal stroke. Exp Neurol. 2005;195(2):407-15.

25. Hurn PD, Koehler RC, Blizzard KK, Traystman RJ. Deferoxamine reduces early metabolic failure associated with severe cerebral ischemic acidosis in dogs. Stroke. 1995;26(4):688-694-695.

26. Wilks MQ, Normandin MD, Yuan H, Cho H, Guo Y, Herisson F, et al. Imaging PEG-like nanoprobes in tumor, transient ischemia, and inflammatory disease models. Bioconjug Chem. 2015;26(6):1061-9.

27. Chen Q, Tang J, Tan L, Guo J, Tao Y, Li L, et al. Intracerebral hematoma contributes to hydrocephalus after intraventricular hemorrhage via aggravating iron accumulation. Stroke. 2015;46(10):2902-8.

28. Strahle JM, Garton T, Bazzi AA, Kilaru H, Garton HJL, Maher CO, et al. Role of hemoglobin and iron in hydrocephalus after neonatal intraventricular hemorrhage. Neurosurgery. 2014;75(6):696-705. discussion 706.

29. Chen Z, Gao C, Hua Y, Keep RF, Muraszko K, Xi G. Role of iron in brain injury after intraventricular hemorrhage. Stroke. 2011;42(2):465-70.

30. Gao C, Du H, Hua Y, Keep RF, Strahle J, Xi G. Role of red blood cell lysis and iron in hydrocephalus after intraventricular hemorrhage. J Cereb Blood Flow Metab. 2014;34(6):1070-5.

31. Meng H, Li F, Hu R, Yuan Y, Gong G, Hu S, et al. Deferoxamine alleviates chronic hydrocephalus after intraventricular hemorrhage through iron chelation and Wnt1/Wnt3a inhibition. Brain Res. 2015;1602:44-52.

32. Okauchi M, Hua Y, Keep RF, Morgenstern LB, Schallert T, Xi G. Deferoxamine treatment for intracerebral hemorrhage in aged rats: therapeutic time window and optimal duration. Stroke. 2010;41(2):375-82.

33. Hatakeyama T, Okauchi M, Hua Y, Keep RF, Xi G. Deferoxamine reduces neuronal death and hematoma lysis after intracerebral hemorrhage in aged rats. Transl Stroke Res. 2013;4(5):546-53.

34. Ni W, Okauchi M, Hatakeyama T, Gu Y, Keep RF, Xi G, et al. Deferoxamine reduces intracerebral hemorrhage-induced white matter damage in aged rats. Exp Neurol. 2015;272:128-34.

35. Gu Y, Hua Y, Keep RF, Morgenstern LB, Xi G. Deferoxamine reduces intracerebral hematoma-induced iron accumulation and neuronal death in piglets. Stroke. 2009:40(6):2241-3.

36. Zhao F, Song S, Liu W, Keep RF, Xi G, Hua Y. Red blood cell lysis and brain tissue-type transglutaminase upregulation in a hippocampal model of intracerebral hemorrhage. Acta Neurochir Suppl. 2011;11:101-5. 
37. Song S, Hua Y, Keep RF, Hoff JT, Xi G. A new hippocampal model for examining intracerebral hemorrhage-related neuronal death: effects of deferoxamine on hemoglobin-induced neuronal death. Stroke. 2007; 38(10):2861-3.

38. Nakamura T, Keep RF, Hua Y, Schallert T, Hoff JT, Xi G. Deferoxamine-induced attenuation of brain edema and neurological deficits in a rat model of intracerebral hemorrhage. J Neurosurg. 2004;100(4):672-8.

39. Huang F-P, Xi G, Keep RF, Hua Y, Nemoianu A, Hoff JT. Brain edema after experimental intracerebral hemorrhage: role of hemoglobin degradation products. J Neurosurg. 2002;96(2):287-93.

40. Song S, Hua Y, Keep RF, He Y, Wang J, Wu J, et al. Deferoxamine reduces brain swelling in a rat model of hippocampal intracerebral hemorrhage. Acta Neurochir Suppl. 2008;105:13-8.

41. Wan S, Hua Y, Keep RF, Hoff JT, Xi G. Deferoxamine reduces CSF free iron levels following intracerebral hemorrhage. Acta Neurochir Suppl. 2006;96: 199-202.

42. He Y, Hua Y, Lee J-Y, Liu W, Keep RF, Wang MM, et al. Brain alpha- and beta-globin expression after intracerebral hemorrhage. Transl Stroke Res. 2010;1(1):48-56.

43. He Y, Wan S, Hua Y, Keep RF, Xi G. Autophagy after experimental intracerebral hemorrhage. J Cereb Blood Flow Metab. 2008;28(5):897-905.

44. Klebe D, Krafft PR, Hoffmann C, Lekic T, Flores JJ, Rolland W, et al. Acute and delayed deferoxamine treatment attenuates long-term sequelae after germinal matrix hemorrhage in neonatal rats. Stroke. 2014;45(8):2475-9.

45. Hishikawa T, Ono S, Ogawa T, Tokunaga K, Sugiu K, Date I. Effects of deferoxamine-activated hypoxia-inducible factor-1 on the brainstem after subarachnoid hemorrhage in rats. Neurosurgery. 2008;62(1):232-240-241.

46. Bilgihan A, Türközkan N, Aricioğlu A, Aykol S, Cevik C, Göksel M. The effect of deferoxamine on brain lipid peroxide levels and Na-K ATPase activity following experimental subarachnoid hemorrhage. Gen Pharmacol. 1994; 25(3):495-7.

47. Utkan T, Sarioglu Y, Kaya T, Akgün M, Göksel M, Solak O. Effect of deferoxamine and sympathectomy on vasospasm following subarachnoid hemorrhage. Pharmacology. 1996;52(6):353-61.

48. Vollmer DG, Hongo K, Ogawa H, Tsukahara T, Kassell NF. A study of the effectiveness of the iron-chelating agent deferoxamine as vasospasm prophylaxis in a rabbit model of subarachnoid hemorrhage. Neurosurgery. 1991;28(1):27-32.

49. Selim M. Treatment with the iron chelator, deferoxamine mesylate, alters serum markers of oxidative stress in stroke patients. Transl Stroke Res. 2010; 1(1):35-9.

50. Selim M, Yeatts S, Goldstein JN, Gomes J, Greenberg S, Morgenstern LB, et al. Safety and tolerability of deferoxamine mesylate in patients with acute intracerebral hemorrhage. Stroke. 2011;42(11):3067-74.

51. Yeatts SD, Palesch $Y$ Y, Moy CS, Selim M. High dose deferoxamine in intracerebral hemorrhage (HI-DEF) trial: rationale, design, and methods. Neurocrit Care. 2013; 19(2):257-66.

\section{Submit your next manuscript to BioMed Central and we will help you at every step:}

- We accept pre-submission inquiries

- Our selector tool helps you to find the most relevant journal

- We provide round the clock customer support

- Convenient online submission

- Thorough peer review

- Inclusion in PubMed and all major indexing services

- Maximum visibility for your research

Submit your manuscript at www.biomedcentral.com/submit
O BioMed Central 